\section{A Jumbo Solution for Quality}

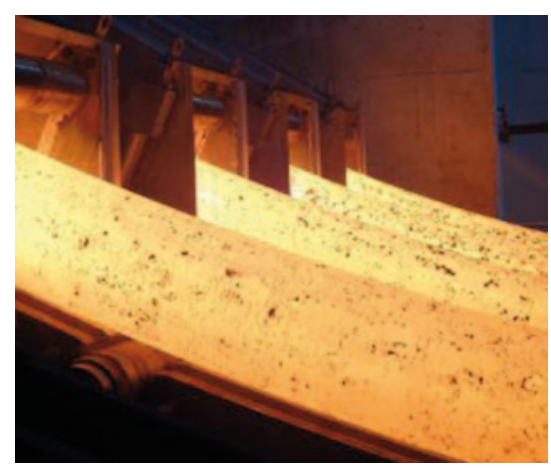

Fig. 1: Casting of 500-mm-diameter round blooms

On July 3, 2013, the new jumbo caster supplied to Changzhou Zhongtian Iron \& Steel Co. Ltd. (Zenith Steel) was started up. With the capability to cast round bloom diameters of up to $600 \mathrm{~mm}$, Zenith Steel has taken a major step forward in the production of highest-quality blooms for most demanding downstream applications. The caster is highlighted by the installation of the latest solutions and technological packages from Siemens VAI.

In April 2011, Siemens VAl received a contract from the Chinese steel producer Zenith Steel to supply a 5-strand bloom caster that allows round blooms to be cast with diameters ranging from $360 \mathrm{~mm}$ to $600 \mathrm{~mm}$ (Fig. 1), and rectangular blooms with cross sections of up to $490 \mathrm{~mm} \times 370 \mathrm{~mm}$. The produced steel grades comprise lowto high-carbon structural steel grades, alloyed and low-alloyed steels, and pipe steel grades. Round blooms with a diameter between $360 \mathrm{~mm}$ and $500 \mathrm{~mm}$ are further processed to seamless pipes, while the largest rounds with a diameter of $600 \mathrm{~mm}$ are used for forging applications. The continuous casting facility has a machine radius of 14 meters and a metallurgical length of 32 meters. With a heat size of approximately 140 tons of steel and casting speeds up to $0.8 \mathrm{~m} / \mathrm{min}$., a total of 1.3 million tons of blooms can be produced per year.

The new caster incorporates many of the core elements and features of Siemens VAl continuous casting technology for the production of highquality steel. Examples range from electromagnetic stirring, soft reduction, the application of advanced online automation and simulation models to the Simetal VAIQ qualityprediction system.

The withdrawal stands are designed in such a way that they are capable of exerting varying degrees of force. Small forces can be applied to support the strand weight without cre- ating any internal cracks or other loadrelated strand defects. The withdrawal units are also capable of exerting high forces when soft reduction is applied during rectangular bloom casting.

\section{Successful Start-Up}

The caster installation commenced in late 2012, and, already by mid-2013, the first blooms with $500 \mathrm{~mm}$ diameters were successfully produced on the new caster. Start-up and commissioning proceeded smoothly to the full satisfaction of the customer. All guarantee figures were met within a short time following first heat, and, in November 2013, the customer signed the final acceptance certificate for round formats.

\section{Authors}

Wolfgang Schönhart, Project Manager, Continuous Casting

Franz Wimmer, Continuous Casting Technologist

Siemens VAI Metals Technologies $\mathrm{GmbH}$

Turmstrase 44 4031 Linz 